\title{
Mentors that Matter: International Student Leadership Development and Mentor Roles
}

\section{Tricia R Shalka ${ }^{\mathrm{a} \otimes}$, Chloe S. Corcoran and Brian T. Magee}

\begin{abstract}
Leadership development has been identified as an important outcome of higher education in the United States. However, relatively few scholars have investigated leadership development outcomes of international students studying in U.S. postsecondary contexts. Using data from the Multi-Institutional Study of Leadership, the purpose of this quantitative study was to investigate the role of mentors in fostering leadership development outcomes for international students. Results suggest that international students whose primary college mentor is a faculty member or a student affairs professional demonstrate higher levels of both socially responsible leadership capacity and leadership self-efficacy than those international students who identify their most significant mentor as another student.
\end{abstract}

Keywords: college students, international students, leadership development, mentorship

\section{Introduction}

In 2015, an estimated 4.6 million international postsecondary students were studying worldwide, representing significant growth from previous decades (ICEF Monitor, 2017). The United States has experienced similar growth patterns of international students. In fact, by the 2015-2016 academic year, international student enrollment in U.S. higher education institutions had increased $185 \%$ from 10 years prior (Institute of International Education [IIE], 2016). However, some scholars have questioned whether this growth in enrollment has been paralleled by sufficient attention to the educational outcomes that international students may derive from their experiences studying abroad in the United States (Lee, 2010; Moores \& Popadiuk, 2011; Nguyen, 2016; Shalka, 2017).

Given a growing international student population (conceptualized in this article as students who have moved away from their home country to the United States), it is critical that both research and practice reflect attention to ensuring international students successfully achieve promoted outcomes of U.S. higher education. For example,

\footnotetext{
a Warner School of Education \& Human Development, University of Rochester.

$\bowtie$ Corresponding author: tshalka@warner.rochester.edu
} 
leadership development has long been heralded as an important outcome for students in U.S. higher education (Council for the Advancement of Standards in Higher Education, 2009; Dugan \& Komives, 2007; Riutta \& Teodorescu, 2014; Roberts, 2007), and college student leadership development is a substantial research focus across a proliferating body of literature (e.g., Campbell, Smith, Dugan, \& Komives, 2012; Dugan \& Komives, 2010; Kodama \& Dugan, 2013). However, relatively few scholars have investigated leadership development of international students (e.g., Collier, Rosch, \& Houston, 2017; Nguyen, 2016; Shalka, 2017). What some of this previous work has unearthed, however, is the importance of mentorship in leadership growth among international students. Yet, this previous research failed to identify the specific roles of mentors who make a difference in international students' leadership development. The purpose of the current study was to address that gap and offer insight into the specific mentorship relationships that can contribute to or detract from leadership development of international students.

\section{Review of Literature}

To frame the current study, several important concepts are engaged in the literature review that follows. First, an overview of the current contexts of international students studying in U.S. higher education and the potential for positive outcomes during their time studying abroad is provided. This framing includes a discussion of some of the dominant ways in which international students have been constructed in the literature. Next, college student leadership development is explored as a desired outcome of U.S. higher education and is connected to previous research that has noted the importance of mentorship in this process.

\section{International Students in the Context of U.S. Higher Education}

Literature about international students has often taken either a deficit approach in relation to the student (e.g., Gautam, Lowery, Mays, \& Durant, 2016; Sherry, Thomas, \& Chui, 2010) or a benefit approach from the perspective of the host country and institution (e.g., Owens, Srivastava, \& Feerasta, 2011). Karram (2013) investigated these dichotomous discourses as signifying tensions between humans and markets in which international students are framed as vulnerable, while host institutions and nations are represented with market share to gain. The deficit perspective has dominated much research about international students and framed this student population as vulnerable, while emphasizing what is not working in their experiences. For example, this body of scholarship has illustrated the ways in which international students struggle in relation to their host country's culture (Gautam et al., 2016; Reynolds \& Constantine, 2007; Sherry et al., 2010; Yan \& Berliner, 2011), language (Gautam et al., 2016; Sherry et al., 2010), and discriminatory climates (Hanassab, 2006; Lee \& Rice, 2007). As a recent discourse analysis study suggests, the deficit perspective is echoed in U.S. academic media in which particular international student populations (in this case Chinese international students) are "othered" and portrayed as deficient (Suspitsyna \& Shalka, in press).

Conversely, literature has addressed what the United States and individual institutions have to gain through international student enrollment. Altbach and Knight (2007) defined 
internationalization as a chosen institutional level response to globalization. As a choice, internationalization is employed for its advantages to a particular organization. In the context of U.S. higher education, international student recruitment is one pathway to such institutional benefits. From this perspective, international students have been framed in literature as "cultural resources" who may "[actively contribute] to the university's strategic goal of global engagement and internationalization" (Urban \& Palmer, 2014, p. 305) or as "stimulus potential" towards local economic gains (Owens et al., 2011, p. 157). Indeed, through the lens of market gain, international students in the United States infuse a tremendous amount of wealth into the economy as well as their host institutions. For the 2015-2016 academic year, international students contributed $\$ 32.8$ billion to the U.S. economy and supported 400,812 jobs (NAFSA, n.d.). Meanwhile, this economic impact is simultaneously of direct importance to individual institutions, as evidenced in discourses about international students as economic units and the "cash cows" of U.S. higher education (Fischer, 2012; Karram, 2013; Stein \& Andreotti, 2016). In fact, some have argued (e.g., Altbach \& Knight, 2007) that such monetary profit potential is a key reason that institutions recruit international students.

Amidst discourses of the vulnerable international student who represents economic gain for institutions (Karram, 2013), the question remains as to what benefits international students receive from their participation in U.S. higher education. Although scholars have suggested that answers to that question have not necessarily been at the forefront of research or practice regarding international students (Moores \& Popadiuk, 2011), there are many examples in the literature that have emphasized the value-added of U.S. higher education for international students. For example, Moores and Popadiuk (2011) investigated the positive dimensions of international students' transitions to their host countries and institutions and identified how students experienced gains in terms of personal development, increasingly complex perspectives, and capacities for perseverance in the face of challenges. Zhao, Kuh, and Carini (2005) unearthed similar dimensions of growth among international students including personal, social, and academic gains during their time abroad.

The current study builds on the trajectory of work that explores the positive outcomes international students derive from their time spent studying in the United States, specifically through the frame of leadership development as such an outcome. Research exploring leadership development of international students in the United States remains sparse, yet several scholars have recently begun to investigate this intersection (e.g., Collier, Rosch, \& Houston, 2017; Nguyen, 2016; Shalka, 2017). However, this recent literature has generally focused on exploring leadership differences between international students and domestic students. The current study, instead, focuses exclusively on international students and leadership, which helps to extend prior work and simultaneously emphasize international student experiences on their own terms rather than in relation to domestic students.

\section{College Student Leadership Development and the Role of Mentorship}

Colleges and universities play fundamental roles in educating the next generation of leaders, with many institutions capturing this as a key element of their missions (Council 
for the Advancement of Standards in Higher Education, 2009; Dugan \& Komives, 2007; Riutta \& Teodorescu, 2014; Roberts, 2007). Additionally, college student leadership experience has been linked to a variety of desired outcomes in higher education including students' civic engagement, capacities to function in diverse environments, and increased attractiveness to potential employers upon graduation (Cress, Astin, Zimmerman-Oster, \& Burkhardt, 2001; National Association of Colleges and Employers, 2017). Consequently, several institutions have dedicated substantial resources to the promotion of leadership development in college students, including funding sources for both personnel and programming (Dugan \& Komives, 2007; Owen, 2009). These efforts arguably have proven worthwhile in the U.S. undergraduate landscape, as research has demonstrated that the collegiate experience results in notable leadership gains during the course of students' time in college (Mayhew et al., 2016; Rosch, Ogolsky, \& Stephens, 2017).

Yet, achieving the mission of developing college students as effective leaders involves multiple dimensions. In recent years, extensive scholarship has identified a myriad of factors that are important to college student leadership development. For instance, key influences on students' leadership development include meaningful conversations and interactions with peers about differences (Dugan \& Komives, 2010; Kodama \& Dugan, 2013; Riutta \& Teodorescu, 2014), participation in service learning (Dugan \& Komives, 2010; Wagner \& Mathison, 2015), development of leadership self-efficacy (Dugan, Kodama, Correia, \& Associates, 2013; Kodama \& Dugan, 2013), and leadership experience through student organizations participation (Garcia, Huerta, Ramirez, \& Patrón, 2017; Kodama \& Dugan, 2013; Martin, Hevel, \& Pascarella, 2012).

As several recent studies suggest, mentorship is among the many dimensions of student experiences that may positively contribute to leadership development outcomes (e.g., Campbell et al., 2012; Dugan et al., 2013; Dugan \& Komives, 2010; Oaks, Duckett, Suddeth, \& Kennedy-Phillips, 2013; Shalka, 2017). Specifically, previous studies illuminated various aspects of the role of the mentor in contributing to college student leadership development. For example, Dugan and Komives (2010) found faculty mentorship to be a particularly strong predictor of college student leadership development, while Campbell et al. (2012) found that being mentored by a student affairs professional relative to a faculty member was a strong predictor. The Campbell et al. study did not find any significant differences in terms of mentorship by a peer or an employer. However, both of these studies focused on general student populations and did not isolate analyses to investigate the experiences of international students.

In one of the few studies that did explore mentorship and leadership in international student populations, Shalka (2017) noted the importance of this type of student support. Specifically, international students in that study appeared to be scoring lower on measures of socially responsible leadership relative to domestic peers. However, the presence of mentorship focused on personal development minimized this difference. What that study did not capture, however, was a nuanced understanding of whether different types of mentors had different effects on international student leadership development. The current study addressed that gap. 


\section{Theoretical Framework}

The current study used two separate constructs to conceptualize college student leadership outcomes. First, this study drew on the social change model of leadership development (Higher Education Research Institute [HERI], 1996). Second, this study also utilized the concept of leadership self-efficacy to articulate a particular aspect of college student leadership capacity. Both of these constructs are briefly outlined below.

Created by a diverse team of leadership educators and scholars, the social change model of leadership development (SCM) was established to provide a theoretical framework that reflected evolving notions of leadership as relational and interactional processes for purposes of socially responsible change (Dugan, 2017; HERI, 1996; Roberts, 2017). Since its development, the SCM has emerged as one of the most widely used theories of conceptualizing and developing college student leadership capacity across higher education contexts both in the United States and around the world (Dugan, 2017; Roberts, 2017). The SCM frames leadership as a process (rather than a position) structured around three values-based domains (Dugan, 2017). The individual domain includes the intrapersonal level values of consciousness of self, congruence, and commitment. The group domain accounts for interpersonal values of leadership processes including collaboration, common purpose, and controversy with civility. The society/community domain then captures leadership processes related to the value of citizenship and being in community with others. These three domains all interact towards the explicit purpose of change in terms of socially responsible actions.

Bandura (1997) articulated self-efficacy as a component of his broader social cognitive theory, and this concept served as the foundation upon which leadership self-efficacy is framed in the current study. Bandura defined self-efficacy as "beliefs in one's capabilities to organize and execute the courses of action required to produce given attainments" (p. 3). Of particular note, Bandura underscored that efficacy is domain-specific and the degree of efficacy that an individual experiences will vary across different activity domains. The current study, then, considered the domain of leadership as one of these particular activity areas where an individual may experience a particular degree of self-efficacy.

As conceptualized by Hannah, Avolio, Luthans, and Harms (2008), leadership selfefficacy is an individual's appraisal and confidence in their "knowledge, skills, and abilities [to] lead others" (p. 669). Studies have suggested leadership self-efficacy as an important component of broader college student leadership development outcomes (Dugan \& Komives, 2010), and identified various conditions that enhance leadership self-efficacy for college students (Dugan, Garland, Jacoby, \& Gasiorski, 2008; Kodama \& Dugan, 2013). Of particular note to the current study, previous research demonstrated mentorship as an intervention that can result in notable growth in leadership self-efficacy (Lester, Hannah, Harms, Vogelgesang, \& Avolio, 2011).

\section{Methodology}

The purpose of this study was to understand if undergraduate international students in the United States experience any differences in leadership development outcomes based on the role of their primary mentor at their university. Two research questions framed 
this investigation. First, do significant differences exist by type of campus mentor in terms of international students' socially responsible leadership development? Second, do significant differences exist by type of campus mentor in terms of international students' leadership self-efficacy?

\section{Data}

Data used in the current study are derived from the 2009 Multi-Institutional Study of Leadership (MSL). The MSL is an international study primarily focused on leadership development of students in higher education. Through a variety of quantitative design measures, the MSL examines various aspects of postsecondary environments and student experiences that contribute to leadership outcomes. The 2009 iteration of the MSL is grounded in the social change model of leadership development (HERI, 1996), which informs how leadership development is conceptualized in the current study.

Two dependent variables are used to assess student leadership outcomes in the current study. First, an adapted version of the Socially Responsible Leadership Scale (SRLS) is engaged as a primary measure of college student leadership development. Developed by Tyree (1998), the SRLS operationalized the social change model of leadership development into a quantitative instrument that measures socially responsible leadership. This instrument uses a 5-point Likert-type scale to assess leadership development along three dimensions of the social change model: individual, group, and citizenship. This scale maintained high reliability in the current study with a Cronbach's a of .97.

Second, this study also used a leadership self-efficacy scale as another dependent variable to assess a slightly different form of leadership outcome relative to socially responsible leadership development. The MSL research team developed the leadership self-efficacy scale to measure students' relative confidence in their capacities to perform various leadership behaviors using a 4-point Likert-type scale. This scale also had high reliability with a Cronbach's a of .88 .

The independent variable in this study identified the role of the participant's most significant mentor in the college environment. This variable was selected so that results could be considered in terms of what relationships may be nurtured within the campus environment. Before respondents were asked questions about mentorship, they were given the following prompt on the MSL instrument to help define and situate mentorship: "A mentor is defined as a person who intentionally assists your growth or connects you to opportunities for career or personal development." Participants were then asked about the frequency with which they may have received mentorship from various people in their lives, which included both those in their college environment (e.g., faculty) and those not in their college environment (e.g., parent/guardian). If participants indicated receiving mentorship from someone in their college environment, they were given a follow-up question that asked them to identify their most significant mentor at their college or university and that person's role. Participants could select from four categories in identifying their most significant mentor at their institution including faculty/instructor, employer, other student, or student affairs professional staff (participants were offered examples including student organization advisor, career counselor, dean of students, and residence hall coordinator). It is important to note that the MSL instrument did not 
identify how mentorship was established. In other words, participants may have acquired mentors through formal and/or informal means.

\section{Sample}

The sample for the current study included 2,556 international students from institutions in the United States. All of these participants were undergraduates. Consistent with other research using the MSL, only participants who completed at least $90 \%$ of the core instrument were considered for inclusion. The current sample included those undergraduate international students who met the $90 \%$ criteria in addition to completing the question that asked them to identity their most significant mentor at their college or university.

Racial diversity of respondents in the current sample was consistent with what might be expected given the countries from which international students were arriving to the United States during the 2008-2009 academic year (IIE, 2009), the timeframe during which data were collected. Participants self-identified in terms of the following: 55.2\% Asian American/Asian, 18.4\% White/Caucasian, 3.6\% Middle Eastern, 7.4\% African American/Black, 0.5\% American Indian/Alaska Native, 7.2\% Latino/Hispanic, and 4.1\% multiracial. Additionally, 9.3\% of participants indicated that their race/ethnicity was not included among the options listed above. Distribution across class years was fairly even with $26.0 \%$ first-years, $22.5 \%$ sophomores, $24.6 \%$ juniors, and $26.9 \%$ seniors. In terms of gender, $54.1 \%$ of participants identified as female, $45.6 \%$ as male, and $0.3 \%$ as transgender.

Students were able to choose from four different categories in identifying their most significant mentor at their college or university, including faculty/instructor, student affairs professional staff, employer, or other student. In the current sample, $50.7 \%$ of students identified a faculty member, $12.1 \%$ a student affairs professional, $5.7 \%$ an employer, and $31.5 \%$ another student. Other questions asked students about additional mentors in their lives, but for the purpose of this study only those who were significant mentors at the student's college are considered in order to ascertain what environmental conditions within the university climate may be important components of international student leadership development.

\section{Analysis}

Descriptive analyses were conducted to examine demographic characteristics of the sample, as well as to identify the roles of undergraduate international students' most significant campus mentors. Next, statistical analyses were conducted to investigate the specific research questions that framed this study. The first research question in this study focused on whether or not differences exist in terms of socially responsible leadership development of international students based on the role of their most significant campus mentors. The second research question explored whether or not differences exist in terms of international students' leadership self-efficacy based on the role of their most significant campus mentors. To answer these two questions, two separate one-way between-groups analysis of variance tests (ANOVAs) were conducted. 


\section{Limitations}

A potential limitation of this study was the decision to focus on students' most significant campus mentor as opposed to looking more broadly across all types of mentorship that international students may receive. This decision was made for two reasons. First, an exclusive focus on a significant mentor in the college environment allows for consideration of the types of mentor relationships that could be shaped and fostered in college environments, whereas mentorship in the community or from families may be less under the purview of institutions. Second, this decision was also informed by limitations of the MSL instrument that only identified a student's most significant mentor from a list of their campus mentors. Questions that addressed students' mentors both on and off campus did not ascertain which of these relationships proved most significant. Thus, it would be difficult to determine how meaningful these other mentor relationships may be.

The emphasis on campus mentors presented in the current study, however, is simultaneously an intentional choice of the research design as well as a possible limitation in that students may in fact have other significant mentorship relationships that are not captured in the current project. In other words, the influence of mentors presented here is limited to a particular set of mentors; although, there may be other mentorship relationships worthy of exploration in how they connect to international students' growth as leaders. Indeed, it could be beneficial to explore mentorship that occurs beyond the campus environment in future studies.

\section{Findings}

Descriptive analyses were conducted to gain insight into the roles of international students' most significant mentors. These analyses were isolated by class year to see if any patterns developed over the course of students' time in higher education. As Table 1 demonstrates, a large proportion of international students identified a faculty member as their most significant campus mentor across class years. However, the second highest proportion of international students selected a peer as their most significant campus mentor. By a student's senior year, still $25 \%$ of international students indicated a peer was their most significant campus mentor. This proportion is particularly noteworthy given the results of the one-way ANOVA analyses to follow.

Table 1. Most significant campus mentor role for international students by class year.

\begin{tabular}{lcccc}
\hline & First year & Sophomore & Junior & Senior \\
\hline Faculty & $46.6 \%$ & $47.0 \%$ & $51.6 \%$ & $57.1 \%$ \\
Student affairs professional & $13.1 \%$ & $14.4 \%$ & $11.8 \%$ & $9.3 \%$ \\
Employer & $3.6 \%$ & $5.0 \%$ & $5.7 \%$ & $8.1 \%$ \\
Other student & $36.7 \%$ & $33.6 \%$ & $30.9 \%$ & $25.4 \%$ \\
\hline
\end{tabular}

To explore the first research question, a one-way between-groups analysis of variance was performed to determine whether the role of the significant campus mentor results in a difference in terms of international students' demonstration of socially responsible 
leadership. The independent variable of the significant mentor's role divided participants into four possible groups: those who identified a faculty member/instructor, a student affairs professional, an employer, or another student. Results of the one-way ANOVA demonstrated a statistically significant difference at the $p<.05$ level in socially responsible leadership as an outcome variable, $F(3,2552)=4.9, p=.00$. However, the effect size was small $\left(\mathrm{h}^{2}=.01\right)$. Post hoc comparisons were conducted to establish the nature of these differences using Tukey's HSD (honestly significant difference) test. These comparisons demonstrated a statistically significant difference between: (a) faculty/instructor $(M=$ 3.88, $S D=0.44)$ and other student $(M=3.81, S D=0.43)$, and; (b) student affairs professional $(M=3.90, S D=0.43)$ and other student $(M=3.81, S D=0.43)$. In other words, international students demonstrated better performance in terms of socially responsible leadership when their significant campus mentor was either a faculty member or student affairs professional rather than another student.

For the second research question, a one-way between-groups analysis of variance was also conducted. This time, differences between groups based on the role of the significant campus mentor were evaluated in terms of international students' capacity for leadership self-efficacy. Results of these analytic procedures also demonstrated a statistically significant difference at the $p<.05$ level, $F(3,2552)=9.9, p=.00$, though the effect size was small $\left(\mathrm{h}^{2}=.01\right)$. To explore these differences, Tukey's HSD test was used. Similar to the pattern noted above for socially responsible leadership, these comparisons demonstrated statistically significant differences between: (a) faculty/instructor $(M=2.97$, $S D=0.67$.) and other student $(M=2.82, S D=0.69)$, and; (b) student affairs professional $(M$ $=3.00, S D=0.68)$ and other student $(M=2.82, S D=0.69)$. Again, this finding suggests that international students tend to demonstrate enhanced capacity for leadership self-efficacy when their significant mentor is either a professor or student affairs professional rather than a peer.

\section{Discussion and Implications}

Results of this study suggested that international students whose most significant college mentor is either a faculty member or a student affairs professional demonstrated higher scores on both socially responsible leadership and leadership self-efficacy than those international students who identified their most significant mentor as another student. This is a significant finding for a variety of reasons, but one immediate implication is related to the percentage of international students who identify a peer as their most significant campus mentor. As Table 1 illustrates, although the percentage of international students who identify their most significant campus mentor as a peer decreases slightly over their time in college, there remains a sizeable proportion of international students who are accessing their primary form of campus mentorship from other students throughout their undergraduate careers. Indeed, by senior year, slightly more than a quarter of international students continued to identify their most significant campus mentor as a peer. This is a concerning trend given the results of the current study that suggest the importance of mentorship via faculty or student affairs staff members for improved leadership development outcomes of international students. 
The results of the current study are also significant in relation to other studies exploring the role of mentorship in college student leadership development. For example, both Dugan and Komives (2010) and Campbell et al. (2012) demonstrated the importance of students being mentored by a professional (faculty member or student affairs administrator) as part of the leadership development process. This is consistent with findings in the current study. However, the current study departs from existing scholarship in notable ways. First, neither Dugan and Komives nor Campbell et al. isolated the experiences of international students in their studies. Additionally, neither of these studies indicated that mentorship by a faculty member or student affairs professional was significantly different in the positive direction than that from a peer, which was the major finding of the current study. Indeed, these findings underscore the unique needs international students may have in U.S. higher education contexts and the importance of both research and practice that seeks to understand these differences relative to what may be useful to the general domestic student population of a particular campus. These unique needs may be supported by other work that has identified how students from different racial backgrounds benefited from different types of mentors (Dugan et al., 2013). Similarly, Kodama and Dugan (2013) noted that when disaggregating data by race, different predictors emerge by racial group for students' leadership self-efficacy outcomes.

Although the current study offered additional insights about the roles of mentors in international students' leadership development trajectories, there are many questions left unanswered that could be explored in future research. First, the current study did not explore how these significant mentorship relationships were established. Were these relationships intentionally fostered or were they organic? Understanding the mechanisms underlying the formation of these mentorship relationships could greatly inform future practice. Second, future research could investigate various contextual influences that support or detract from international students establishing significant mentorship relationships that contribute to leadership development. Environmental contexts such as living on or off campus, being involved in campus organizations, or participating in research with professors are all possible situations in which students may connect with faculty or student affairs staff in meaningful ways that could be assessed in future studies. Finally, leadership in this study is conceptualized through a theoretical framework developed in the United States, the social change model of leadership (HERI, 1996). Although there is evidence of the cross-cultural transferability of this form of leadership (Dugan, Rossetti Morosini, \& Beazley, 2011), it would be useful in future research to better understand the utility of this form of leadership from the perspective of international graduates, both those who remain in the United States and those who may return to their home countries or other nations.

Several implications for practice are evident from the findings in the current study. First, results presented here demonstrated the important role that faculty and student affairs mentors may play for international students and their leadership development. This finding speaks to the importance of campuses structuring international student programs and services to intentionally foster students' meaningful connections with professional role models early on. This could be achieved through formal mentorship programs with faculty and staff, or even in terms of workshops that provide international students with 
tangible skills for how to identify and foster such mentorship relationships. Second, peer mentorship may be an important tool for helping international students acclimate and adjust to their host institution (Thomson \& Esses, 2016), yet results of the current study suggested that this should not be an end point for how institutions conceptualize mentorship for international students, particularly if leadership development outcomes are important. Finally, while both faculty and student affairs professionals emerged as important mentors in the current study, the percentages of international students who cited a student affairs staff member as their most significant campus mentor were relatively low (ranging from a low of $9.3 \%$ during senior year and a high of $14.4 \%$ during sophomore year). This raises the question as to what may be behind these numbers. Are student affairs units doing enough to adequately internationalize their support and services to connect with and appeal to the needs of international students? Given how different student services can look at institutions around the globe, are student affairs practitioners doing enough on U.S. campuses to translate their roles to international students who may not have a frame of reference from their own national contexts? These are questions worthy of consideration, particularly given the important role of student affairs mentorship for international students as identified in the current study.

\section{Conclusion}

Current and historical trend data suggest that international students will continue to represent a significant portion of the U.S. higher education community (IIE, 2016). As the numbers of international students who choose to study in the United States continues to rise, we are offered the opportunity in higher education organizations to reflect on the quality of the experience we are offering international students. As the current study revealed, international students may face unique needs in their pathways to the promises of U.S. higher education, in this case, leadership development outcomes. Specifically, international students' leadership development benefitted from mentors who were faculty members or student affairs professionals rather than other students. This finding is more nuanced than previous similar research investigating leadership development of domestic students. Moving forward, both research and practice must continue to investigate the unique aspects of international student experiences that support value-added elements of their collegiate experiences. This is a critical component of ensuring international students are receiving an equitable and high quality experience while abroad.

\section{References}

Altbach, P. G. \& Knight, J. (2007). The internationalization of higher education: Motivations and realities. Journal of Studies in International Education, 11(3/4), 290-305.

Bandura, A. (1997). Self-efficacy: The exercise of control. W. H. Freeman, New York, NY.

Campbell, C. M., Smith, M., Dugan, J. P., \& Komives, S. R. (2012). Mentors and college student leadership outcomes: The importance of position and process. The Review of Higher Education, 35(4), 595-625.

Collier, D. A., Rosch, D. M., \& Houston, D. A. (2017). Effects of participation in formal leadership training in international students compared to domestic students: A national 
study. Journal of Leadership Education, 16(2), 148-165.

Cress, C. M., Astin, H. S., Zimmerman-Oster, K., \& Burkhardt, J. C. (2001). Developmental outcomes of college students' involvement in leadership activities. Journal of College Student Development, 42(1), 15-27.

Dugan, J. P. (2017). Leadership theory: Cultivating critical perspectives. Jossey Bass, San Francisco, CA.

Dugan, J. P., Garland, J. L., Jacoby, B., \& Gasiorski, A. (2008). Understanding commuter student self-efficacy for leadership: A within-group analysis. NASPA Journal, 45(2), 282310.

Dugan, J. P., Kodama, C., Correia, B., \& Associates (2013). Multi-Institutional Study of Leadership insight report: Leadership program delivery.

Dugan, J. P. \& Komives, S. R. (2007). Developing leadership capacity in college students: Findings from a national study. A report from the Multi-Institutional Study of Leadership. College Park, MD.

Dugan, J. P. \& Komives, S. R. (2010). Influences on college students' capacities for socially responsible leadership. Journal of College Student Development, 51(5), 525-549.

Dugan, J. P., Morosini, A. M. R., \& Beazley, M. R. (2011). Cultural transferability of socially responsible leadership: Findings from the United States and Mexico. Journal of College Student Development, 52(4), 456-474.

Fischer, K. (2012). 'Fess up: Foreign students are cash cows. The Chronicle of Higher Education.

Garcia, G. A., Huerta, A. H., Ramirez, J. J., \& Patrón, O. E. (2017). Contexts that matter to the leadership development of Latino male college students: A mixed methods perspective. Journal of College Student Development, 58(1), 1-18.

Gautam, C., Lowery, C. L., Mays, C., \& Durant, D. (2016). Challenges for global learners: A qualitative study of the concerns and difficulties of international students. Journal of International Students, 6(2), 501-526.

Hanassab, S. (2006). Diversity, international students, and perceived discrimination: Implications for educators and counselors. Journal of Studies in International Education, 10(2), 157-172.

Hannah, S. T., Avolio, B. J., Luthans, F., \& Harms, P. D. (2008). Leadership efficacy: Review and future directions. The Leadership Quarterly, 19, 669-692.

Karram, G. L. (2013). International students as lucrative markets or vulnerable populations: A critical discourse analysis of national and institutional events in four nations. Canadian and International Education, 42(1), 1-13.

Kodama, C. M. \& Dugan, J. P. (2013). Leveraging leadership efficacy for college students: Disaggregating data to examine unique predictors by race. Equity \& Excellence in Education, 46(2), 184-201.

Lee, J. J. (2010). International students' experiences and attitudes at a US host institution: Self-reports and future recommendations. Journal of Research in International Education, 9(1), 66-84.

Lee, J. J. \& Rice, C. (2007). Welcome to America? International student perceptions of discrimination. Higher Education, 53(3), 381-409. 
Lester, P. B., Hannah, S. T., Harms, P. D., Vogelgesang, G. R., \& Avolio, B. J. (2011). Mentoring impact on leader efficacy development: A field experiment. Academy of Management Learning \& Education, 10(3), 409-429.

Martin, G. L., Hevel, M. S., \& Pascarella, E. T. (2012). Do fraternities and sororities enhance socially responsible leadership? Journal of Student Affairs Research and Practice, 49(3), 267-284.

Mayhew, M. J., Rockenbach, A. N., Bowman, N. A., Seifert, T. A., Wolniak, G. E., \& P.T.Terenzini (2016). How college affects students (Volume 3): 21st century evidence that higher education works. Jossey-Bass, San Francisco, CA.

Monitor, I. C. E. F. (2017). OECD charts a slowing of international mobility growth.

Moores, L. \& Popadiuk, N. (2011). Positive aspects of international student transitions: A qualitative inquiry. Journal of College Student Development, 52(3), 291-306.

((n.d, N.) The United States of America benefits from international students: 2015-2016 fact sheet.

Nguyen, D. H. K. (2016). Student success through leadership self-efficacy: A comparison of international and domestic students. Journal of International Students, 6(4), 829-842.

Oaks, D. J., Duckett, K., Suddeth, T., \& Kennedy-Phillips, L. (2013). Leadership development and the African American male college student experience. Journal of College \& Character, 14(4), 331-340.

Owen, J. E. (2009). A snapshot of collegiate leadership programs: Data and implications from the. volume 16.

Owens, D. L., Srivastava, P., \& Feerasta, A. (2011). Viewing international students as state stimulus potential: Current perceptions and future possibilities. Journal of Marketing for Higher Education, 21(2), 157-179.

Reynolds, A. L. \& Constantine, M. G. (2007). Cultural adjustment difficulties and career development of international college students. Journal of Career Assessment, 15(3), 338350.

Riutta, S. \& Teodorescu, D. (2014). Leadership development on a diverse campus. Journal of College Student Development, 55(8), 830-836.

Roberts, D. C. (2007). Deeper learning in leadership: Helping college students find the potential within. Jossey-Bass, San Francisco, CA.

Roberts, D. C. (2017). Transitions and transformations in leadership. pages 5-16, San Francisco, CA. Jossey-Bass.

Rosch, D., Ogolsky, B., \& Stephens, C. M. (2017). Trajectories of student leadership development through training: An analysis by gender, race, and prior exposure. Journal of College Student Development, 58(8), 1184-1200.

Shalka, T. R. (2017). The impact of mentorship on leadership development outcomes of international students. Journal of Diversity in Higher Education, 10(2), 136-148.

Sherry, M., Thomas, P., \& Chui, W. H. (2010). International students: A vulnerable student population. Higher Education, 60(1), 33-46.

Stein, S. \& Andreotti, V. D. O. (2016). Cash, competition, or charity: International students and the global imaginary. Higher Education, 72, 225-239.

Suspitsyna, T. \& Shalka, T. R. (in press). The Chinese international student as a (post)colonial other: An analysis of cultural representations in a U.S. media discourse. 
The Review of Higher Education.

Thomson, C. \& Esses, V. M. (2016). Helping the transition: Mentorship to support international students. in Canada. Journal of International Students, 6(4), 873-886.

Tyree, T. M. (1998). Designing an instrument to measure socially responsible leadership using the social change model of leadership development. Dissertation Abstracts International, 59(6). AAT 983693.

Urban, E. L. \& Palmer, L. B. (2014). International students as a resource for internationalization of higher education. Journal of Studies in International Education, 18(4), 305-324.

Wagner, W. \& Mathison, P. (2015). Connecting to communities: Powerful pedagogies for leading for social change. volume 145, pages 85-96, San Francisco, CA. Jossey-Bass.

Yan, K. \& Berliner, D. C. (2011). An examination of individual level factors in stress and coping processes: Perspectives of Chinese international students in the United States. Journal of College Student Development, 52(5), 523-542.

Zhao, C. M., Kuh, G. D., \& Carini, R. M. (2005). A comparison of international student and American student engagement in effective educational practices. The Journal of Higher Education, 76(2), 209-231.

\section{Author biography}

Tricia R Shalka is an assistant professor in the higher education program at the Warner School of Education \& Human Development at the University of Rochester. Her research interests include the impacts of trauma on college students, leadership development, and international students.

Chloe S. Corcoran is a PhD student in the higher education program at the Warner School of Education \& Human Development at the University of Rochester. Her research interests include diversity and inclusion, international education, and the concepts of space and place in higher education.

Brian T. Magee is an associate director of Wilson Commons Student Activities and a doctoral student at the Warner School of Education \& Human Development, both at the University of Rochester. His research interests focus on college student leadership development through programming, mentorship, and intentional experiential learning experiences. 